\title{
Process mapping in healthcare: a systematic review
}

\author{
Grazia Antonacci ${ }^{1,2^{*}}$, Laura Lennox', James Barlow ${ }^{2}$, Liz Evans ${ }^{3}$ and Julie Reed ${ }^{3}$
}

\begin{abstract}
Introduction: Process mapping (PM) supports better understanding of complex systems and adaptation of improvement interventions to their local context. However, there is little research on its use in healthcare. This study (i) proposes a conceptual framework outlining quality criteria to guide the effective implementation, evaluation and reporting of PM in healthcare; (ii) reviews published PM cases to identify context and quality of PM application, and the reported benefits of using PM in healthcare.

Methods: We developed the conceptual framework by reviewing methodological guidance on PM and empirical literature on its use in healthcare improvement interventions. We conducted a systematic review of empirical literature using PRISMA (Preferred Reporting Items for Systematic Reviews and Meta-Analyses) methodology. Inclusion criteria were: full text empirical study; describing the process through which PM has been applied in a healthcare setting; published in English. Databases searched are: Medline, Embase, HMIC-Health Management Information Consortium, CINAHL-Cumulative Index to Nursing and Allied Health Literature, Scopus. Two independent reviewers extracted and analysed data. Each manuscript underwent line by line coding. The conceptual framework was used to evaluate adherence of empirical studies to the identified PM quality criteria. Context in which PM is used and benefits of using PM were coded using an inductive thematic analysis approach.

Results: The framework outlines quality criteria for each PM phase: (i) preparation, planning and process identification, (ii) data and information gathering, (iii) process map generation, (iv) analysis, (v) taking it forward. PM is used in a variety of settings and approaches to improvement. None of the reviewed studies $(N=105)$ met all ten quality criteria; $7 \%$ were compliant with $8 / 10$ or $9 / 10$ criteria. $45 \%$ of studies reported that PM was generated through multi-professional meetings and 15\% reported patient involvement. Studies highlighted the value of PM in navigating the complexity characterising healthcare improvement interventions.
\end{abstract}

Conclusion: The full potential of PM is inhibited by variance in reporting and poor adherence to underpinning principles. Greater rigour in the application of the method is required. We encourage the use and further development of the proposed framework to support training, application and reporting of PM.

Trial Registration: Prospero ID: CRD42017082140

Keywords: Process, Mapping, Health care, Quality, Improvement, Methods, Systematic review

\footnotetext{
* Correspondence: g.antonacci@imperial.ac.uk

${ }^{1}$ Department of Primary Care and Public Health, Imperial College London,

National Institute of Health Research (NIHR) Applied Research Collaboration

(ARC) Northwest London, London, UK

${ }^{2}$ Business School, Centre for Health Economics and Policy Innovation (CHEPI),

Imperial College London, London, UK

Full list of author information is available at the end of the article
}

(c) The Author(s). 2021 Open Access This article is licensed under a Creative Commons Attribution 4.0 International License, which permits use, sharing, adaptation, distribution and reproduction in any medium or format, as long as you give appropriate credit to the original author(s) and the source, provide a link to the Creative Commons licence, and indicate if changes were made. The images or other third party material in this article are included in the article's Creative Commons licence, unless indicated otherwise in a credit line to the material. If material is not included in the article's Creative Commons licence and your intended use is not permitted by statutory regulation or exceeds the permitted use, you will need to obtain permission directly from the copyright holder. To view a copy of this licence, visit http://creativecommons.org/licenses/by/4.0/ The Creative Commons Public Domain Dedication waiver (http://creativecommons.org/publicdomain/zero/1.0/) applies to the data made available in this article, unless otherwise stated in a credit line to the data. 


\section{Introduction}

There is a growing awareness that quality and safety failures in healthcare are attributable more to systems and processes than to human errors [1-4]. To address this, healthcare leaders are increasingly applying quality improvement (QI) and process-oriented management practices from other industries including Lean, Six Sigma, Failure Mode Effects Analysis (FMEA), Failure Mode, Effects, Criticality Analysis (FMECA), and operational research and process-oriented costing approaches such as Time-Driven Activity-Based Costing (TDABC) [5-8].

Applying QI methodology is challenging as healthcare processes are highly variable, distributed and multidisciplinary, involving stakeholders with differing interests and motivations [9-15]. Research shows that the success of QI interventions is heavily influenced by their context of implementation [16-18]. Developing interventions that are adapted to the local context and setting is an essential component of successful QI [19-21], along with engagement of stakeholders [22-24]. Process mapping (PM) has the potential to support QI projects in healthcare by engaging stakeholders to create a shared understanding of the systems they are trying to change [25-29]. However, there is little research on the use of PM in healthcare and whether it is achieving its full potential. The term 'process mapping' is used to describe several approaches and techniques. Here we refer to the "entire approach that leads to a holistic understanding of the process under review" [12, 30].

Research shows that the full benefits of PM are accomplished when it is used throughout all the stages of a QI project to plan, implement, monitor and evaluate interventions [12, 29, 31-33]. However, the application of PM within QI initiatives has proved challenging due to the limited time clinicians can devote to it and their limited knowledge of PM methods [34-36].

Although more informed and systematic use of PM in the design and management of healthcare delivery is advocated [37, 38], there is poor evidence on the use of PM and its effectiveness in healthcare [39-41]. To advance current knowledge on PM and improve its use in practice, we need greater insight into how it works in different contexts, the mechanisms underlying its successful use, and challenges to its implementation $[42,43]$.

There is currently no systematic review of the use of PM in healthcare practice. Most published literature only describes empirical studies of individual interventions using PM. There is very limited information on the range and type of healthcare settings in which PM has been used or the benefits of its use. This problem is compounded by the lack of formal criteria to guide the implementation, evaluation and reporting of PM. Some methodological guides focus on PM in healthcare improvement initiatives [29, 31, 32, 44]; none are based on the structured review of the research evidence. Limited knowledge of the use of PM as a QI method in healthcare hinders its wider adoption [45]. Therefore, increased awareness of its possible applications and benefits, as well as evidence-based quality criteria for its use, are needed.

This paper reviews the empirical literature and methodological guidance on PM to increase understanding of its use in healthcare to: (1) develop a conceptual framework identifying different phases in PM, with quality criteria for each, to guide the effective implementation, assessment and reporting of this method; (2) identify the context of use of PM in healthcare QI projects; (3) assess adherence of the application of PM as described in empirical literature to the proposed conceptual framework quality criteria and (4) explore the reported evidence for the benefits of using PM in improvement work.

\section{Methods}

\section{Conceptual framework development}

Given there was limited literature available on the use of PM and little practical guidance on its use in healthcare, we recognised the need to draw on evidence from other relevant fields such as manufacturing and other service industries. We conducted a snowballing review of methodological literature on PM in both healthcare and non-healthcare settings (Fig. 1, online supplementary appendix 1). The objective was to identify recommended good practice methods for conducting PM [46]. We identified the most cited studies by searching online databases (Google Scholar, Scopus, Medline, Embase) with keywords derived from our research questions. We then screened citations and reference lists from these sources and included relevant studies. Given the high number of irrelevant articles derived from the online database search, the snowballing technique was very useful to

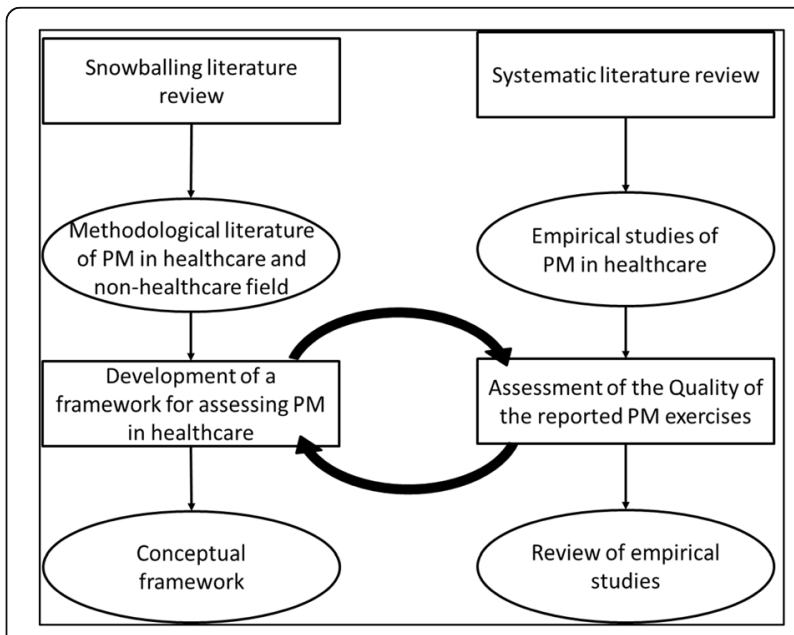

Fig. 1 Literature review - Study Method 
identify the few available methodological studies on PM, as it allowed us to find grey literature, that might be missed by conventional online search methods. We then assessed methodological guidelines (online supplementary appendix 1) and empirical literature selected in the systematic review (2.2, Fig. 1) and through a process of inductive and deductive analysis we developed a conceptual framework identifying overarching quality criteria for each phase of the PM process (3.2, Fig. 2). These criteria were discussed by all authors and selected if they could be applied to a wide range of PM approaches and QI project types. Iterative development of the framework continued as new ideas emerged through discussions and feedback from experts and practitioners.

\section{Systematic literature review}

A systematic literature review of empirical research reporting on the use of PM in healthcare was performed following PRISMA (Preferred Reporting Items for Systematic Reviews and Meta-Analyses) standards [49] and registered on PROSPERO (ID: CRD42017082140).

\section{Search and information sources}

The search was designed to identify English-language empirical studies describing the use of PM in healthcare. The definition of search strategies was supported by an expert medical librarian. Databases searched were Medline (from 1946), Embase (from 1974), HMICHealth Management Information Consortium (from 1979), CINAHL-Cumulative Index to Nursing and Allied Health Literature (from 1937), Scopus (from 1960). The last search date was 9 November 2019. Search terms used were "process map" as a free text search term in title, abstract and keywords for all the selected databases except Scopus, where the search was "process map" AND "health". No restrictions on time were imposed on the search.

One author (GA) performed the search and extraction of article references and abstracts.

\section{Data collection process and study selection}

Inclusion criteria were: full text empirical study; describing the process through which PM has been applied in a healthcare setting; published in English. Methodological

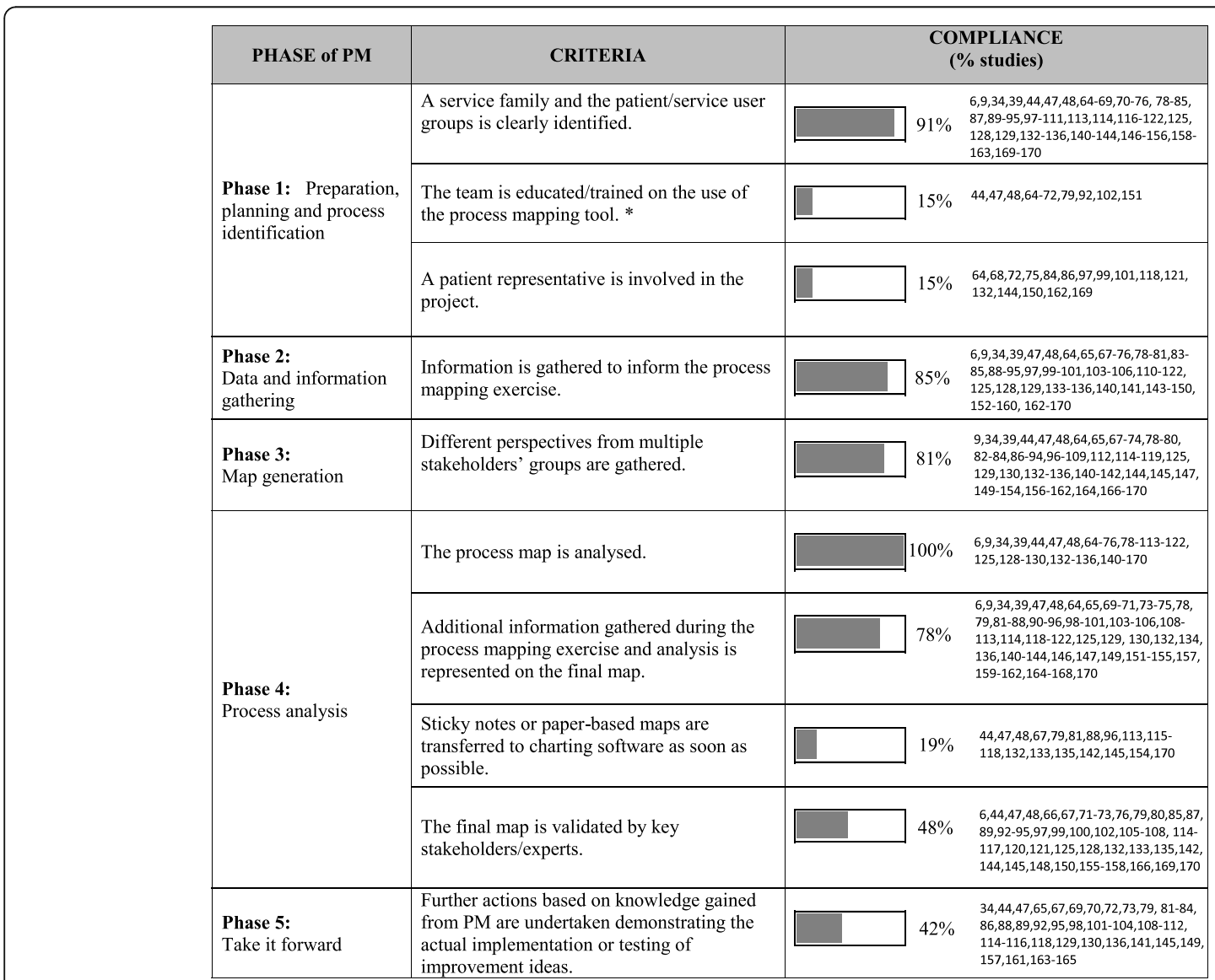

Fig. 2 Conceptual framework for process mapping describing a. Phases of PM b. overarching criteria / standards for the PM process (* including 2 cases saying training was not needed as team members already had experience of PM $[47,48])$ 
studies, posters and conference proceedings were excluded. Articles were first screened by title and abstract by GA. Two reviewers (GA, LL) then independently assessed $20 \%$ of full-text articles to test the objectivity of selection criteria, which were then refined. GA and LL independently continued the selection process for the identified articles. Disagreements between reviewers occurred in $4 \%$ of cases and were resolved through discussion between all authors.

\section{Data extraction}

A data extraction form was designed to collect general study information alongside a set of features characterising a PM exercise (e.g. adherence to main criteria for each phase of PM, way in which PM was created, software used to draw the process map, use of online supplements to report complete process maps), from a wide range of projects with different characteristics. The development of the data extraction sheet (online supplementary appendix 3) was based on the findings from the snowballing review of literature on PM methodologies and a preliminary screening of all the full text articles included in the empirical research literature review. This initial version was pilot-tested on the $20 \%$ of articles (purposively selected to represent different contexts of use of PM) and progressively refined during the data extraction process. Each step in the refinement of the data collection sheet was agreed by all the authors.

Data were extracted from included studies independently by two authors (GA, LL). When disagreements occurred, the other reviewers were involved, and agreement was reached through consensus.

\section{Data synthesis and analysis}

The analysis was performed independently by two authors (GA, LL) and discussed with the other reviewers. Each manuscript underwent line by line coding. Context in which PM is used (3.3) and benefits of using PM in improvement work (3.5) were identified from the selected studies and coded using an inductive thematic analysis approach [50-52]. Compliance of application of PM to the conceptual framework criteria (3.4) was assessed by coding empirical articles' adherence to each of the quality criteria and counting the number of studies reporting on the presence of corresponding data item [46]. To ensure accuracy and control for bias in the analysis, all stages of the analysis were progressively discussed by authors and various QI experts and practitioners (researchers, improvement science managers, project managers, and data analysts from the $\mathrm{Na}-$ tional Institute of Health Research (NIHR) Collaboration for Leadership in Applied Health Research and Care Northwest London (CLAHRC NWL) who were trained in improvement science systematic approaches and tools) [53-57]. Results were summarised using descriptive summaries as well as ratios (for details on the analysis process see online supplementary appendix 2 ).

\section{Quality assessment and risk of bias}

The quality of each study and risk of bias were assessed using the Critical Appraisal Skills Programme (CASP) checklist $[58,59]$. Two authors $(\mathrm{GA}, \mathrm{JB})$ rated the articles independently with disagreements resolved through consensus (see online supplementary appendix 4). CASP was selected because several of the articles included in the review were qualitative studies and covered a wide range of QI projects. Assessing the effectiveness of the projects in which PM has been used was not relevant for this review, therefore results of individual studies were not analyzed. As reported in other qualitative reviews, articles were not excluded or stratified by risk bias [50, 51, 60-63]. Rather, we considered the relative contribution of low/high quality studies in the analysis phase [50, 61]. Moreover, as the review is based on information reported in the selected empirical literature, publication bias as well as bias due to the reporter and the selection of studies may have affected the results of this study (see Limitation section).

\section{Results}

\section{The conceptual framework}

Six studies were identified in the snowballing literature review of methodological publications on PM in healthcare and other service and manufacturing industries to develop the conceptual framework (online supplementary appendix 1). The conceptual framework (Fig. 2) described below provides quality criteria for each of the five phases characterizing the process of PM taken from the methodological literature.

\section{(i) Preparation, planning and process identification}

The service family under analysis and those who will use the process/service (e.g. patients/services users/customers etc.) should be clearly identified and representatives from these groups should be involved in the project. It's also important that participants have the right skills required to participate in the PM exercise, which might vary depending on the type of project, modelling language and methods used for the analysis. Training should be provided to PM participants to fill skills gaps, if needed. For example, for simple PM exercises this might include a quick introduction to the PM method, while for PM exercises involving more sophisticated approaches (e.g. Six Sigma) and/or more structured modelling languages (e.g. Business Process Modelling Notation), a more technical intensive training might be appropriate. 


\section{(ii) Data and information gathering}

Information should be gathered to inform the PM exercise. In addition to multi-disciplinary meetings, data can be collected using different approaches, such as direct observations, interviews, self-reported patient experiences, analysis of electronic health records or other relevant databases, literature or document analysis.

\section{(iii) Process map generation}

Different perspectives should be gathered by people having diverse roles in the process, each bringing their view and knowledge of the process under analysis.

\section{(iv) Analysis}

The process map should be analysed to identify gaps in the systems and opportunities for improvement. The final process map should be checked for accuracy and validated by key stakeholders/experts. During the analysis phase it's good practice to annotate the process map with information derived from the analysis (e.g. activity durations, resources involved) and transfer paper-based maps in an electronic format. Having a tidy electronic version of the process map supports the analysis and the documentation of the PM exercise and it's also useful to disseminate and share the map with interested parties or those involved in the process for comments and validation.

\section{(v) Taking it forward}

Process maps should be used to guide process improvement initiatives. Improvement ideas and actions generated throughout the PM exercise should be implemented to improve current systems and practice.

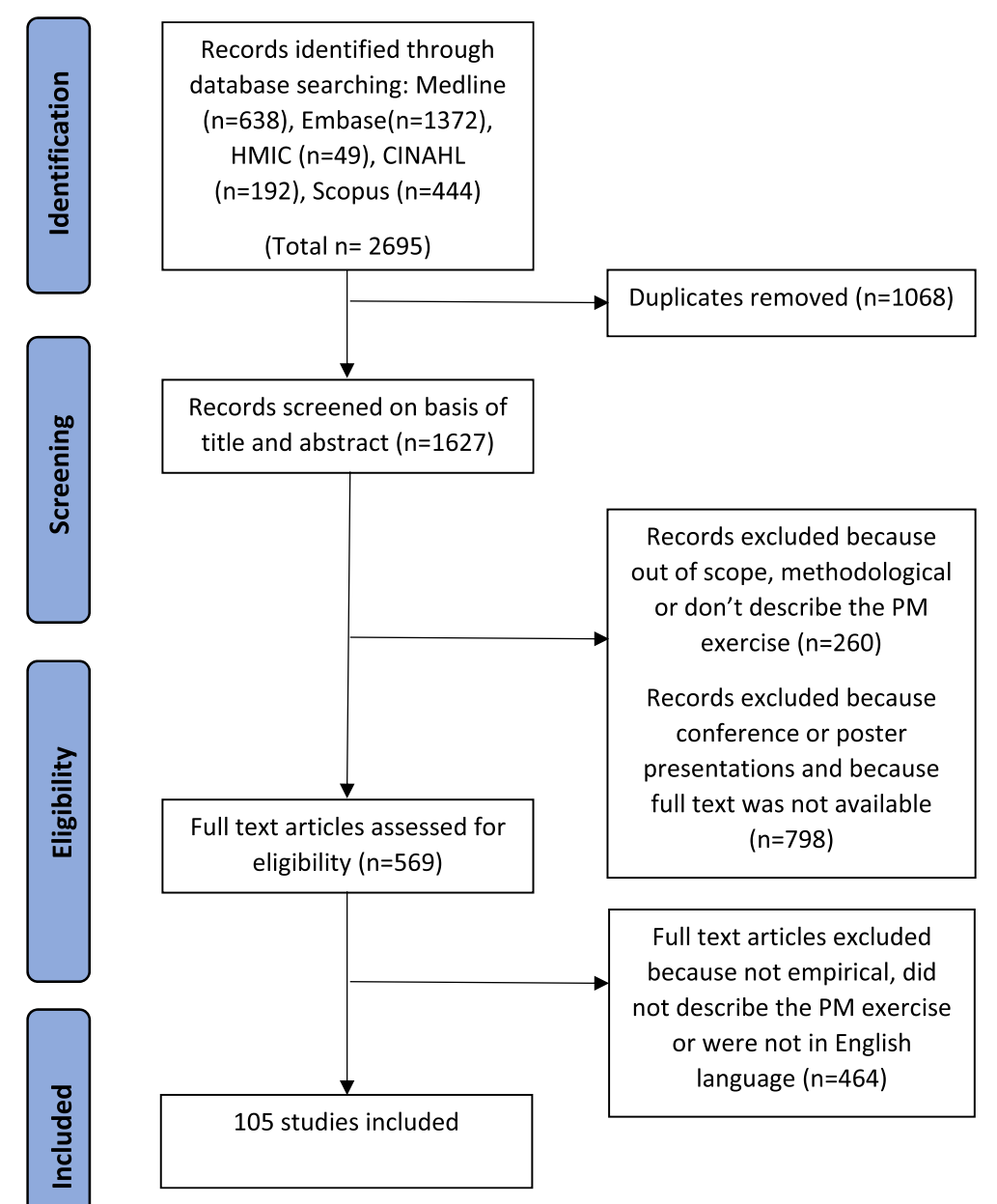

Fig. 3 PRISMA Diagram. Description of study selection process 


\section{General study characteristics}

The study selection process for the systematic review of empirical studies using PM is reported in Fig. 3. A total of 105 articles met the inclusion criteria and were included in the review (online supplementary appendix 3). Study quality was moderate-high with $31 \%$ study scoring $10 / 10$, $43 \%$ scoring $9 / 10,20 \%$ scoring $8 / 10$ and $6 \%$ scoring 6-7/10 (online supplementary appendix 4). $86 \%$ were published in or after 2010 and $65 \%$ were conducted in the USA and UK (online supplementary appendix 5).

\section{Context in which PM is used}

PM exercises were reported from a wide range of healthcare settings including, in-patient services (32\%), multiple settings (29\%), outpatient (11\%), AEE (8\%), community care (6\%), care provided in other settings (5\%), primary care (5\%), prevention and health promotion (3\%) and laboratory services (3\%). The most common type of projects reporting the use of PM in healthcare were process improvement/QI initiatives (68\%), which include the use of FMEA/FMECA (11\%) and Lean and Six Sigma (12\%) approaches. Use of PM in health information technologies (HIT) projects was reported in $10 \%$ of studies. A few studies outline its use to develop and share evidence-based recommendations and pathways (9\%). Others reported using PM to identify care process steps within activity-based costing methodologies $(6 \%)$ or to provide a visual representation of patient journeys (5\%). Only 3\% of papers described the use of PM in integrated care pathway (ICP) projects. (Fig. 4).

\section{Compliance of application of PM to the conceptual framework criteria}

We assessed all empirical studies against the conceptual framework quality criteria for each phase of PM. The key findings are displayed in Fig. 2.

No study reached overall compliance for all 10 the criteria. Only 7 studies (7\%) adhered to either 9/10 (2\%) criteria or $8 / 10$ criteria (5\%). For five of these seven studies the criteria about involvement of those who would be using the processes (e.g. patient involvement) was not met. Most studies adhered to $7 / 10$ (15\%), 6/10 (32\%) and 5/10 (35\%) of the criteria. The remaining $10 \%$ of studies were compliant to $4 / 10$ criteria.

Phase 1: Most projects clearly identified a service family and the patient/service user group (91\%), but patient representative involvement was only reported in a small number of projects (15\%). Team member training in the technique prior the PM exercise was reported in only $15 \%$ of projects. This was usually delivered throughout meetings and by using examples [44, 64-70], while in some cases this included intensive QI training [71, 72].

Phase 2: $85 \%$ of the studies stated that data and information had been gathered to inform the PM exercise as a substitute for (55\%), or in addition to (30\%), the group

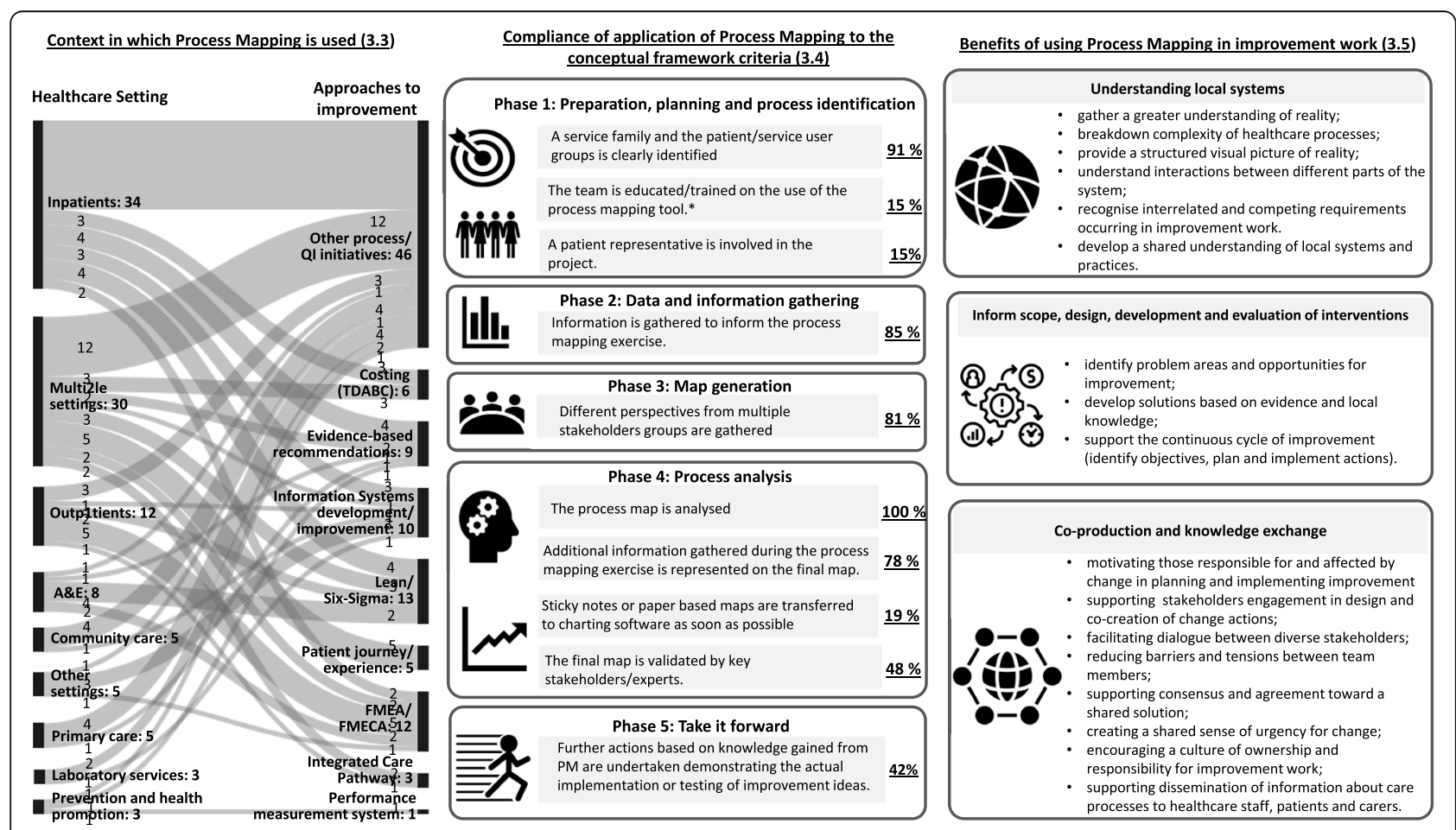

Fig. 4 Context in which PM is used, compliance of application of PM to the conceptual framework criteria and benefits of using PM to address complexity of improvement work. (* including 2 cases saying training was not needed as team members already had experience of PM [47, 48]) 
knowledge generated in the facilitated process mapping sessions. This included evidence-based best practice recommendations [34-155], interviews [64, 73-148, 154, $156,158,160]$, and more detailed approaches such as observations, operational data collection, time-andmotion studies, and video footage [48, 78-81, 141, 143146, 150, 159, 163-169].

Phase 3: $81 \%$ of studies included perspectives from diverse stakeholders. In less than half of the studies (45\%), the maps were generated by multiple stakeholder groups; in the remaining studies, maps were generated by researchers. Most projects using industrial engineering approaches created maps in multi-stakeholder meetings (69\%).

Phase 4: All 105 studies reported that the process map was analysed. How and at what point the analysis was carried out varied significantly, depending on the type of project being reported. Most studies (91\%) reported that the map was created to represent current state practice. Four projects [82-85] reported both current state and ideal or future state maps, while 5 describe the ideal or future state process $[65,86-89]$. For example, in $T D A B C$ projects the analysis is focused on process costs and is mainly completed after the current state process map is created [90-95]. In projects implementing evidencebased recommendations, a process analysis was completed before the creation of the ideal or future state process map [89]. Most studies (78\%) reported that additional information gathered during the PM exercise such as delays, safety problems, or flow of information, resources and activity - is represented on the final map. Only 19\% of studies reported the use of charting software to draw the process map or to make a tidy version of the paper-based map, and only $48 \%$ of studies specified that the PM exercise had been reviewed for accuracy and confirmed by key stakeholders or external experts.

Phase 5: $42 \%$ of studies reported on the implementation of actions following the PM exercise. The remainder identified process or system issues that needed improvement but did not report taking action.

\section{Benefits of using PM in improvement work}

We identified the benefits of using PM in improvement initiatives described in the reviewed empirical literature and grouped them into three areas: (i) understanding local systems, (ii) inform scope, design, development and evaluation of interventions and (iii) co-production and knowledge exchange. (Fig. 4).

\section{(i) Understanding local systems}

Studies reported that QI teams gained a more realistic understanding of current practice because PM allowed them to gather knowledge from people directly involved in the process under analysis and provided a visual representation of current or enhanced processes $[65,83,96$, 142]. The studies show that PM is a tool to break-down the complexity characterizing healthcare, by providing improvement teams with a structured picture of complex processes, using information from process stakeholders holding different roles and perspectives [34, 88, 90, 96, 98-100, 140]. Diverse views elicited during PM help improvement teams gain a shared understanding of local practices and underlying systemic issues. For example, PM has been found particularly useful to disaggregate care process and identify costs for each process step [90-95] as well as to understand interactions between different parts of healthcare systems. For example, in ICP projects the use of PM to understand systems helped to improve coordination of care across different settings and networks [86, 87, 101], while in FMEA projects it helped to identify potential systems failures [48, 66-68, 100, 102-107].

\section{(ii) Inform scope, design, development and evaluation of} interventions.

The identification of actual constraints and opportunities within local systems helped assessment of problem areas and development of improvement solutions grounded in research evidence and local knowledge [65, $76,79,81,92,96,108-110,149,151]$. The use of PM before the implementation of Information Systems (IS) has been shown to support project members with diverse backgrounds achieve a shared understanding of the system and has been reported as crucial for solving design challenges [88, 111-115]. Some studies describe how PM has also been used to assess actual care processes against recognised evidence-based standards [79, 99]. Reviewed studies also show how if used throughout the entire project, PM can play a role in the success of improvement initiatives by supporting continuous improvement. In this respect, PM has been found to be particularly useful for clarifying the scope of projects, targeting the intervention and planning improvement actions $[9,79,116,161]$.

\section{(iii) Co-production and knowledge exchange.}

PM was reported to be particularly useful to engage and motivate project stakeholders in designing and implementing change. Some studies report that PM supported the effective design of HIT by enhancing the involvement of process stakeholders [88, 111-115]. Studies also describe how greater understanding of different perspectives provided by PM encouraged a culture of ownership and responsibility for improvement work [34, 65, 66, 81, 92, 118, 119]. For example, within ICP 
projects, PM allowed the clarification and reassessment of the roles and responsibilities within the team [86, 87, 101]. Other studies highlight how participation in PM helped to establish sense of urgency in clinicians regarding patient safety issues, thus enhancing their engagement $[81,92,157]$. Reviewed studies also show that the capacity of PM to facilitate the dialogue between diverse stakeholders helps to smooth barriers and tensions occurring during improvement projects or reach consensus on solutions [65, 66, 71, 73, 81, 92, 103, 118, 119]. For example, some studies reported how PM helped to promote the integration of health services across different settings by developing clinical evidence-based recommendations agreed among different healthcare professionals [74, 86, 87, 89]. Finally, studies describe how PM can be a valuable tool for documenting a care process for further dissemination [170]. This is beneficial, for example, in helping to inform patients and carers about their expected journey [75, 99, 120-122] or to support training and education of healthcare professionals [81, 101, 152, 153, 162].

\section{Discussion}

The use of PM within healthcare improvement projects helps to support understanding of complex healthcare systems and adaptation of improvement interventions to their local context. We reviewed methodological guidance on PM, peer-reviewed empirical literature, and developed a conceptual framework to guide effective implementation, assessment, and reporting of PM in healthcare. We assessed adherence of 105 empirical studies to quality criteria outlined in a newly created conceptual framework. Comparison of methodological guidelines and empirical literature helped to identify common features characterising the use of PM across the selected studies. We also identified reported context of use and benefits of using PM in improvement work.

To our knowledge, this is the first systematic literature review exploring the use of PM in healthcare improvement projects. The review demonstrates that PM is used in projects to improve quality and safety in a wide range of healthcare settings. These projects focus on different QI tools and approaches, and use PM either as a standalone methodology or as a support for other QI methods.

Using the conceptual framework, we found inconsistencies in reporting and in adherence to PM quality criteria. None of the studies adhered to all the criteria and only $7 \%$ studies adhered to $8 / 10$ or $9 / 10$ criteria. Assessment of adherence was, however, challenging due to variation in reporting of PM exercises across studies. This is attributable both to the diversity of the contexts for using PM and lack of standardised reporting requirements. Analysis of the reviewed studies suggests that poor adherence with quality criteria reflects not just problems in the reporting of PM, but also the conduct of the method.

Although for most reviewed studies, views of different stakeholders were gathered, only $15 \%$ reported the involvement of those who would be using the processes such as patients/ service users/ customers. Moreover, less than half $(45 \%)$ clearly reported that process maps were generated through multi-professional meetings. This suggests that some benefits of PM may not have been realised in these studies, as failure to engage all stakeholders is unlikely to produce realistic process maps or support successful patient-centred QI initiatives. If PM is conducted without appropriate stakeholder participation, some of the benefits derived from the social interactions, such as empathy between professional groups and agreement for shared solutions, are inhibited [12]. Two of the studies identified in the systematic review reported that the limited involvement of clinical staff was related to the difficultly of relieving them from their daily job $[102,117]$ but reasons for poor patient involvement should be further investigated [24].

Only 14 of the reviewed studies report training in PM techniques as part of the project. Limited training in PM techniques may explain the lack of discussion or consideration of the process modelling language used to draw the process map in the reviewed studies. This finding confirms previous research stating that most projects in healthcare only use flowchart diagrams, regardless the variety of process modelling techniques and tools available [123]. The choice of modelling language used is important in describing and understanding systems analysed with PM and overlooking these aspects can impact its effective use [124]. Furthermore, training project teams in QI is important not only to improve participants' technical skills, but also to enhance their engagement in the project $[69,103]$.

Some studies reported that they had to balance the rigorous use of the PM method with resource and time constraints they had to face in practice $[48,93,103,113$, 117, 125]. Despite reviewed studies demonstrating poor adherence to the identified PM quality criteria, they describe a number of benefits derived from its use in healthcare improvement projects. This demonstrates the key role played by PM in addressing the challenge of designing and implementing change in complex systems. Using PM in improvement work helps to achieve the strategic principles identified by the Successful Healthcare Improvement from Translating Evidence in Complex Systems (SHIFT-evidence) framework (act scientifically and pragmatically, embrace complexity, engage and empower) [54]. The capacity of PM to bring together diverse stakeholder perspectives and provide a visual representation of the system is key to address the 
complexity which characterizes healthcare processes. Within QI projects, PM helped to provide a shared understanding of the reality of complex systems and facilitated dialogue between team members. This increased engagement of project participants and eased their agreement on common solutions to problems, thus supporting two levers recognised as important for successful improvement in complex systems: knowledge coproduction and the definition of shared goals across stakeholders $[126,127]$.

The use of PM as a monitoring and evaluation tool [9, $12,64,119,128-130]$ appeared to be out of scope of application by many QI teams. Most of the articles we reviewed focus on use of PM to better understand systems only at the early stages of an improvement initiative or to visualise and disseminate process maps as the "output" of the project. Only $42 \%$ of the reviewed studies describe actions undertaken following the PM exercise, suggesting there is still more to know on how PM influences action and impact in overall improvement efforts.

Findings from this literature review show there is still much room for improvement in the use and reporting of PM as a QI method. Limited adherence to recommended practice for PM is a finding consistent with the assessment of fidelity reported for other QI methods [46, 131].

\section{Implications for practitioners and academics}

We unpacked the black box of PM as a QI method and outlined quality criteria to guide its systematic use and reporting. Improving the quality of reporting of PM exercises would enhance transparency, encourage appropriate use of PM in practice, and support the definition of a common language to describe the process of PM [24]. We encourage practitioners and researchers to use and test the validity of our conceptual framework when implementing or reporting PM. We also suggest further development of reporting guidance for PM exercises and their use as a starting point in the design of prospective studies exploring the effectiveness of the method. Our findings show that improvements in reporting are required not only to systematically describe the "process" of PM but also for representation of the process map, as we found that many articles report only a partial or sample representation of the process map developed. Online versions of published articles or online supplements [48, $66,68,69,90,132-136]$ could provide more detailed process maps as these are often difficult to display in printed versions of journals. Improvements in the way process maps are represented and reported might increase the effectiveness of PM as a key QI method. For example, annotating the process map with operational (e.g. waiting times, activity durations, waste/ value), cost (e.g. resources required to perform each activity), patient experience or other project data (e.g. areas targeted or changed by various plan-do-study-act cycles), can be helpful to visually identify gaps in the systems and document the process analysis throughout the project. Previous studies also demonstrated that successful implementation of QI initiatives depends not only on the conformance to methodological guidelines, but is greatly influenced by contextual factors (leadership, organisational culture, etc.) [16, 137-139]. Our study has not taken into account the influence of context on PM exercises, because these factors cannot be assessed by analysis of the literature. While the main contribution of this study is in identifying quality criteria to support a more rigorous use and reporting of PM, we encourage practitioners and researchers to consider the influence of contextual factors on the effective use of QI approaches.

\section{Further research}

There is a need for further empirical research to explore the impact of improvement initiative context on practical implementation of PM. We partially explored how $\mathrm{PM}$ is used in practice by improvement teams in the NHS in a previous empirical study investigating benefits and success factors of PM in a sample of QI projects [12]. However, most of the projects included in this study [12] used the same methodological approach to PM, (multi-stakeholder meetings to generate the process maps). Further empirical research is needed to test whether our findings hold in QI projects developed by teams using different approaches to conduct the PM exercise, as identified in this literature review (e.g. when PM is used within Six Sigma or Lean approaches). Further literature and empirical research could also explore the representation of process maps in more detail. This would provide a wider perspective on how process activities can be represented and annotated with a variety of information (e.g. value/waste, bottlenecks, constraints, patient experience) and how this can influence the effective use of PM within improvement initiatives.

\section{Limitations}

There are some limitations due to the search process. The database search could have included other search terms such as "process model"," "process design" or "system design"", but the authors agreed that the effort required to screen the resulting records was not justified by the purpose and boundaries of the present study.

A key limitation is due to the fact that the systematic review is based on PM exercises as described in the selected empirical literature and not on the analysis of actual practice. This implies that results might be affected by reporting bias and selection of studies, as well as publication bias. The content of publications heavily 
depends on what journals accept for publication and on the limited space allowed. Therefore, projects using specific approaches (e.g. TDABC, Lean or IS development) are less likely to present a detailed description of the PM process, compared to other process improvement projects. Successful projects are more likely to be published than studies reporting less successful interventions, which may be equally useful for knowledge generation. Bias could also arise because we only searched Englishlanguage papers. However, our objective was not to perform an exhaustive review of all the studies applying PM techniques in healthcare, nor to assess the effectiveness of PM, but to provide a representative overview of the use of PM as reported in empirical literature.

Another limitation is due to the fact that PM exercises were usually reported as a part of a wider project. Clearly distinguishing the component attributable to PM from that associated with the whole project was therefore not always straightforward. We addressed this limitation in the development of the data item sheet and the conceptual framework, as well as in the data collection and analysis phase. For example, we decided not to quantitatively assess the different roles involved in the PM exercise, because it was not always clear if and how all team members were involved in the PM exercise. Furthermore, we evaluated the actual implementation of the recommendations derived by the PM exercise, considering the improvement actions reported in respect of the whole project.

Finally, within the included studies we found three papers [120-122] which seemed to derive from the same project. We addressed this bias in the analysis and summary phase by discounting the patterns emerging from common characteristics of these three studies.

\section{Conclusions}

$\mathrm{PM}$ is at the heart of a range of different improvement projects in healthcare. Its effective use is often a fundamental component of successful QI initiatives. If appropriately used, PM brings together perspectives of diverse stakeholders to harness tacit knowledge and understand complex processes, as well as to find common solutions and enhance team engagement. However, variance in reporting and lack of compliance with guiding principles underpinning its effective use may inhibit its full potential in healthcare improvement initiatives, and in sharing learning between initiatives. Greater scientific rigor in the application and reporting of PM is required to increase its effectiveness as a method for improvement and advance the field of improvement science.

The conceptual framework proposed in this paper provides generalisable quality criteria to help "unpack the black box" of PM across a variety of settings and problems in healthcare. We encourage the use and further development of these criteria to guide future adoption of PM and for reporting and evaluating its efficacy. A better understanding of the circumstances surrounding decisions about deployment of mechanisms supporting QI methods, such as PM, is needed in order to increase their effectiveness. Greater recognition of the benefits of PM, as well as training in this method for healthcare professionals and improvement leaders would also contribute to its more extensive and appropriate use in practice.

\section{Abbreviations}

CASP: Critical Appraisal Skills Programme; CLAHRC: Collaboration for Leadership in Applied Health Research and Care; FMEA: Failure Mode Effects Analysis; FMECA: Failure Mode, Effects, Criticality Analysis; HIT: Health Information Technologies; ICP: Integrated Care Pathway; NIHR: National Institute of Health Research; PM: Process Mapping; PRISMA: Preferred Reporting Items for Systematic Reviews and Meta-Analyses; QI: Quality Improvement; TDABC: Time-Driven Activity-Based Costing

\section{Supplementary Information}

The online version contains supplementary material available at https://doi. org/10.1186/s12913-021-06254-1.

Additional file 1: Supplemental_Material_1. Online supplementary appendix 1, Methodological studies selected in the snowballing search. Description of data: details on the methodological studies used to develop the conceptual framework.

Additional file 2: Supplemental_Material_2. Online supplementary appendix 2, Systematic literature review - Analysis process. Description of data: description of the data analysis process.

Additional file 3: Supplemental_Material_3. Online supplementary appendix 3 - Analysis codes and data extraction details. Description of data: description of the analysis codes and data extraction sheet with the details of data extracted for each article included in the systematic review.

Additional file 4: Supplemental_Material_4. Online supplementary appendix 4, Quality assessment using the Critical Appraisal Skills Programme (CASP) checklist. Description of data: rating of each article included in the systematic review according to the CASP checklist's items.

Additional file 5: Supplemental_Material_5. Online supplementary appendix 5, Characteristics of empirical studies. Description of data: general characteristics of the studies included in the systematic review.

\section{Acknowledgements}

We acknowledge the National Institute of Health Research (NIHR) Collaboration for Leadership in Applied Health Research and Care (CLAHRC) Northwest London team for contributing to shape the scope of this systematic review and for supporting the development and validation of the conceptual framework.

\section{Authors' contributions}

GA identified methodological guidance on Process Mapping and performed the search and extraction of articles references and abstracts for the systematic review. GA and LL defined the selection criteria, independently screened and selected the articles, designed the data extraction form and independently extracted data from included studies. GA and JB assessed quality of each study and risk of bias by rating articles included in the systematic review independently using the CASP checklist. JR and LE contributed to the development of themes for the analysis of benefits of Process Mapping. All authors read and approved the final manuscript and contributed to: the development of the research questions, the development and validation of the conceptual framework, the validation of 
the data extraction sheet, resolve discrepancies between reviewers occurring during the analysis phase.

\section{Funding}

This research was funded by the National Institute for Health Research (NIHR) Collaboration for Leadership in Applied Health Research and Care Northwest London (CLAHRC NWL), now recommissioned as NIHR Applied Research Collaboration Northwest London (ARC NWL). The views expressed in this publication are those of the author(s) and not necessarily those of the NIHR or the Department of Health and Social Care.

\section{Availability of data and materials}

All data generated or analysed during this study are included in this published article [and its supplementary information files].

\section{Declarations}

Ethics approval and consent to participate

Not applicable.

\section{Consent for publication}

Not applicable.

\section{Competing interests}

The authors declare that they have no competing interests.

\section{Author details}

${ }^{1}$ Department of Primary Care and Public Health, Imperial College London, National Institute of Health Research (NIHR) Applied Research Collaboration (ARC) Northwest London, London, UK. ${ }^{2}$ Business School, Centre for Health Economics and Policy Innovation (CHEPI), Imperial College London, London, UK. ${ }^{3}$ Department of Primary Care and Public Health, Imperial College London, National Institute of Health Research (NIHR) Collaboration for Leadership in Applied Health Research and Care (CLAHRC) Northwest London, London, UK.

Received: 19 September 2020 Accepted: 8 March 2021 Published online: 14 April 2021

\section{References}

1. Chassin MR, Becher EC. The wrong patient. Ann Intern Med. 2002;136:826. https://doi.org/10.7326/0003-4819-136-11-200206040-00012.

2. Gaba DM, Singer SJ, Sinaiko AD, Bowen JD, Ciavarelli AP. Differences in safety climate between hospital personnel and naval aviators. Hum Factors. 2003;45(2):173-85. https://doi.org/10.1518/hfes.45.2.175.27238.

3. Klein JG. Five pitfalls in decisions about diagnosis and prescribing. BMJ. 2005;330:781-3. https://doi.org/10.1136/bmj.330.7494.781.

4. Reason J. Human error. 1 edition. Cambridge England. New York: Cambridge University Press; 1991.

5. Kruskal JB, Reedy A, Pascal L, Rosen MP, Boiselle PM. Quality initiatives: lean approach to improving performance and efficiency in a radiology department. RadioGraphics. 2012;32(2):573-87. https://doi.org/10.1148/ rg.322115128.

6. Colligan L, Anderson JE, Potts HW, et al. Does the process map influence the outcome of quality improvement work?A comparison of a sequential flow diagram and a hierarchical task analysis diagram. BMC Health Services Res. 2010;10(1):7. https://doi.org/10.1186/1472-6963-10-7.

7. Niemeijer GC, Trip A, de Jong LJ, et al. Impact of 5 Years of Lean Six Sigma in a University Medical Center: Quality Management in Health Care. 2012;21: 262, 8. https://doi.org/10.1097/QMH.0b013e31826e74b7.

8. Robbins J, Garman AN, Song PH, McAlearney AS. How high-performance work systems drive health care value: an examination of leading process improvement strategies. Quality Management in Healthcare. 2012;21(3):188202. https://doi.org/10.1097/QMH.0b013e31825e88f6.

9. Barach P, Johnson JK. Understanding the complexity of redesigning care around the clinical microsystem. BMJ Quality \& Safety. 2006;15(suppl 1):i106. https://doi.org/10.1136/qshc.2005.015859.

10. Poulymenopoulou M, Malamateniou F, Vassilacopoulos G. Specifying workflow process requirements for an emergency medical service. J Med Syst. 2003;27:325-35. https://doi.org/10.1023/A:1023701219563.
11. Lenz R, Reichert M. IT support for healthcare processes - premises, challenges, perspectives. Data Knowl Eng. 2007;61:39-58. https://doi.org/1 0.1016/j.datak.2006.04.007.

12. Antonacci $G$, Reed JE, Lennox L, Barlow J. The use of process mapping in healthcare quality improvement projects. Health Serv Manag Res. 2018; 0951484818770411(2):74-84. https://doi.org/10.1177/0951484818770411.

13. Rebuge Á, Ferreira DR. Business process analysis in healthcare environments: a methodology based on process mining. Inf Syst. 2012;37(2):99-116. https://doi.org/10.1016/j.is.2011.01.003.

14. Bartz M. Patientenpfade: Ein Instrument zur Prozessoptimierung im Krankenhaus. Saarbrücken: VDM Verlag Dr. Müller; 2006.

15. von Reinersdorff AB. Strategische Krankenhausführung. Vom lean management zum balanced hospital management. Bern: Huber; 2007.

16. Kaplan HC, Provost LP, Froehle CM, et al. The Model for Understanding Success in Quality (MUSIQ): building a theory of context in healthcare quality improvement. BMJ Qual Safety. 2011;bmjqs-2011-000010. https://doi. org/10.1136/bmjqs-2011-000010.

17. McCormack B, Kitson A, Harvey G, et al. Getting evidence into practice: the meaning of 'context. J Adv Nurs. 2002;38:94-104. https://doi.org/10.1046/ j.1365-2648.2002.02150.x.

18. Pfadenhauer LM, Gerhardus A, Mozygemba K, Lysdahl KB, Booth A, Hofmann B, Wahlster P, Polus S, Burns J, Brereton L, Rehfuess E. Making sense of complexity in context and implementation: the context and implementation of complex interventions (CICl) framework. Implementation Sci. 2017;12(1):21. https://doi.org/10.1186/s13012-017-0552-5.

19. Plsek PE, Greenhalgh T. The challenge of complexity in health care. BMJ. 2001;323:625-8. https://doi.org/10.1136/bmj.323.7313.625.

20. Greenhalgh T, Robert G, Macfarlane F, et al. Diffusion of innovations in service organizations: systematic review and recommendations. The Milbank Quarterly. 2004;82(4):581-629. https://doi.org/10.1111/j.0887-3 78X.2004.00325.x.

21. Vos L, Chalmers SE, Dückers ML, et al. Towards an organisation-wide process-oriented organisation of care: a literature review. Implement Sci. 2011;6:8. https://doi.org/10.1186/1748-5908-6-8.

22. Jones D, Mitchell A. Lean thinking for the NHS. London: NHS confederation; 2006.

23. Panella M, Marchisio S, Di Stanislao F. Reducing clinical variations with clinical pathways: do pathways work? Int J Qual Health Care. 2003;15:509_ 21. https://doi.org/10.1093/intqhc/mzg057.

24. Ocloo J, Matthews R. From tokenism to empowerment: progressing patient and public involvement in healthcare improvement. BMJ Qual Saf. 2016;25: 626-32. https://doi.org/10.1136/bmjqs-2015-004839.

25. Hughes RG. Tools and Strategies for Quality Improvement and Patient Safety. In: Hughes RG, ed. Patient Safety and Quality: An Evidence-Based Handbook for Nurses. Rockville (MD): : Agency for Healthcare Research and Quality (US) 2008. http://www.ncbi.nlm.nih.gov/books/NBK2682/. Accessed 3 Feb 2018.

26. Taylor AJ, Randall C. Process mapping: enhancing the implementation of the Liverpool Care Pathway. Int J Palliat Nurs. 2007;13:163-7. https://doi. org/10.12968/ijpn.2007.13.4.23489.

27. Ben-Tovim DI, Dougherty ML, O'Connell TJ, McGrath KM. Patient journeys: the process of clinical redesign. Med J Aust. 2008;188(S6):S14-7. https://doi. org/10.5694/j.1326-5377.2008.tb01668.x.

28. King DL, Ben-Tovim DI, Bassham J. Redesigning emergency department patient flows: application of lean thinking to health care. EMA Emerg Med Australas. 2006;18:391-7. https://doi.org/10.1111/j.1742-6723.2006.00872.x.

29. NHS Institute for Innovation and Improvement. Improvement Leaders' Guide. Process Mapping, analysis and redesign. General improvement skills. 2005.https://www.england.nhs.uk/improvement-hub/wp-content/uploads/ sites/44/2017/11/ILG-1.2-Process-Mapping-Analysis-and-Redesign.pdf. Accessed 9 Jul 2020.

30. Jacka JM, Keller PJ. Business process mapping: improving customer satisfaction. Hoboken: Wiley; 2009.

31. Jackson TL. Mapping clinical value streams. 1st ed. Boca Raton: Routledge; 2013.

32. Jamso TTM, Mavkupt Hydes T. Process mapping the patient journey : an introduction. BMJ. 2010;341(aug13 1):394-7. https://doi.org/10.1136/ bmj.c4078.

33. Wooldridge AR, Carayon P, Hundt AS, et al. SEIPS-based process modeling in primary care. Appl Ergon. 2017;60:240-54. https://doi.org/10.1016/j.a pergo.2016.11.010 
34. Bonzo SM, McLain D, Avnet MS. Process modeling in the operating room: a socio-technical systems perspective. Syst Eng. 2016;19:267-77. https://doi. org/10.1002/sys.21343.

35. Kuljis J, Paul RJ, Stergioulas LK. Can health care benefit from modeling and simulation methods in the same way as business and manufacturing has? In: 2007 Winter Simulation Conference; 2007. p. 1449-53. https://doi.org/1 0.1109/WSC.2007.4419755.

36. De Regge $M$, Gemmel $P$, Verhaeghe R, et al. Aligning service processes to the nature of care in hospitals: an exploratory study of the impact of variation. Oper Manag Res. 2015;8(1-2):32-47. https://doi.org/10.1007/s12063-015-0098-0.

37. Edwards N. Can quality improvement be used to change the wider healthcare system? BMJ Quality \& Safety. 2005;14(2):75. https://doi.org/1 0.1136/ashc.2005.013748.

38. Clarkson PJ, Buckle P, Coleman R, Stubbs D, Ward J, Jarrett J, Lane R, Bound J. Design for patient safety: a review of the effectiveness of design in the UK health service. J Eng Des. 2004;15(2):123-40. https://doi.org/10.1080/ 09544820310001617711.

39. Santana S, Redondo P. Process mapping: a tool to foster intra- and interorganizational coordination in primary care. Family Medicine and Primary Care Review. 2018;20:41-6. https://doi.org/10.5114/fmpcr.2017.72150.

40. Shojania KG, Grimshaw JM. Evidence-based quality improvement: the state of the science. Health Aff. 2005;24(1):138-50. https://doi.org/10.1377/hltha ff.24.1.138.

41. Auerbach AD, Landefeld CS, Shojania KG. The tension between needing to improve care and knowing how to do it. N Engl J Med. 2007;357:608-13. https://doi.org/10.1056/NEJMsb070738.

42. Grol R, Baker R, Moss F. Quality improvement research: understanding the science of change in health care. BMJ Quality \& Safety 2002;11:110-1. doi: https://doi.org/10.1136/qhc.11.2.110, 2, 111.

43. Walshe K. Pseudoinnovation: the development and spread of healthcare quality improvement methodologies. Int J Qual Health Care. 2009;21(3):1539. https://doi.org/10.1093/intqhc/mzp012.

44. McLaughlin N, Rodstein J, Burke MA, et al. Demystifying process mapping: a key step in neurosurgical quality improvement initiatives. Neurosurgery. 2014;75:99-109. https://doi.org/10.1227/NEU.0000000000000360.

45. Jun GT, Ward J, Morris Z, et al. Health care process modelling: which method when? Int J Qual Health Care. 2009;21:214-24. https://doi.org/10.1 093/intahc/mzp016.

46. Taylor MJ, McNicholas C, Nicolay C, et al. Systematic review of the application of the plan-do-study-act method to improve quality in healthcare. BMJ Qual Saf. 2013;:bmjqs-2013-001862. https://doi.org/10.1136/ bmjqs-2013-001862

47. Prairie BA, Foster T. Improving prenatal HIV screening with tailored educational interventions: an approach to guideline implementation. Qual Saf Health Care. 2010;19:e52. https://doi.org/10.1136/qshc.2008.031922.

48. Prabhakaran S, Khorzad R, Brown A, Nannicelli AP, Khare R, Holl JL. Academic-community hospital comparison of vulnerabilities in door-toneedle process for acute ischemic stroke. Circ Cardiovasc Qual Outcomes. 2015:8(6 suppl 3):S148-54. https://doi.org/10.1161/ CIRCOUTCOMES.115.002085

49. Liberati A, Altman DG, Tetzlaff J, et al. The PRISMA statement for reporting systematic reviews and meta-analyses of studies that evaluate healthcare interventions: explanation and elaboration. BMJ. 2009;339. https://doi.org/1 0.1136/bmj.b2700

50. Thomas J, Harden A. Methods for the thematic synthesis of qualitative research in systematic reviews. BMC Med Res Methodol. 2008;8(1):45. https://doi.org/10.1186/1471-2288-8-45.

51. Bergs J, Lambrechts F, Simons P, Vlayen A, Marneffe W, Hellings J, Cleemput I, Vandijck D. Barriers and facilitators related to the implementation of surgical safety checklists: a systematic review of the qualitative evidence. BMJ Qual Saf. 2015;24(12):776-86. https://doi.org/10.1136/bmjqs-2015-004021.

52. Creswell JW, Poth CN. Qualitative inquiry and research design: choosing among five approaches. Thousand Oaks: SAGE Publications; 2016.

53. Caldwell SE, Mays N. Studying policy implementation using a macro, meso and micro frame analysis: the case of the collaboration for leadership in Applied Health Research \& Care (CLAHRC) programme nationally and in north West London. Health Research Policy and Systems. 2012;10:32. https:// doi.org/10.1186/1478-4505-10-32.

54. Reed JE, Howe C, Doyle C, Bell D. Simple rules for evidence translation in complex systems: a qualitative study. BMC Med. 2018;16(1):92. https://doi. org/10.1186/s12916-018-1076-9.
55. Evans S, Scarbrough $\mathrm{H}$. Supporting knowledge translation through collaborative translational research initiatives: "bridging" versus "blurring" boundary-spanning approaches in the UK CLAHRC initiative. Soc Sci Med. 2014;106:119-27. https://doi.org/10.1016/j.socscimed.2014.01.025.

56. CLAHRC Northwest London. http://clahrc-northwestlondon.nihr.ac.uk/. Accessed 9 Jul 2020

57. About | CLAHRC Partnership Programme. https://clahrcprojects.co.uk/about. Accessed 9 Jul 2020

58. CASP-Qualitative-Checklist-2018.pdf. https://casp-uk.net/wp-content/uploa ds/2018/01/CASP-Qualitative-Checklist-2018.pdf. Accessed 9 Jul 2020.

59. Hannes K. Chapter 4: Critical appraisal of qualitative research. In: Noyes J, Booth A, Hannes K, Harden A, Harris J, Lewin S, Lockwood C. eds. Supplementary Guidance for Inclusion of Qualitative Research in Cochrane Systematic Reviews of Interventions. Version 1 (updated August 2011). 2011. http://cqrmg.cochra ne.org/supplemental-handbook-guidance. Accessed 9 Jul 2020.

60. Taylor N, Clay-Williams R, Hogden E, Braithwaite J, Groene O. High performing hospitals: a qualitative systematic review of associated factors and practical strategies for improvement. BMC Health Serv Res. 2015;15(1): 244. https://doi.org/10.1186/s12913-015-0879-z.

61. Vaughn VM, Saint S, Krein SL, et al. Characteristics of healthcare organisations struggling to improve quality: results from a systematic review of qualitative studies. BMJ Qual Saf. 2019;28:74-84. https://doi.org/10.1136/ bmjas-2017-007573.

62. Dixon-Woods M, Bonas S, Booth A, et al. How can systematic reviews incorporate qualitative research? A critical perspective. Qual Res. 2006;6:2744. https://doi.org/10.1177/1468794106058867.

63. Daly J, Willis $K$, Small R, et al. A hierarchy of evidence for assessing qualitative health research. J Clin Epidemiol. 2007;60:43-9. https://doi.org/1 0.1016/j.jclinepi.2006.03.014.

64. Weingart BSN, Spencer J, Buia S, et al. Medication safety of five oral chemotherapies: a proactive risk assessment. J Oncol Pract. 2011;7:2-6. https://doi.org/10.1200/JOP.2010.000064.

65. de Bucourt M, Busse R, Guttler F, et al. Process mapping of PTA and stent placement in a university hospital interventional radiology department. Insights imaging. 2012;3(4):329-36. https://doi.org/10.1007/ s13244-012-0147-2.

66. Walsh KE, Mazor KM, Roblin D, Biggins C, Wagner JL, Houlahan K, Li JW, Keuker C, Wasilewski-Masker K, Donovan J, Kanaan A, Weingart SN. Multisite parentcentered risk assessment to reduce pediatric oral chemotherapy errors. J Oncol Pract. 2013;9(1):e1-7. https://doi.org/10.1200/JOP.2012.000601.

67. Schuller BW, Burns A, Ceilley EA, et al. Failure mode and effects analysis: a community practice perspective. J appl clin med phys. 2017;18:258-67. https://doi.org/10.1002/acm2.12190

68. Mattsson TO, Lipczak H, Pottegård A. Patient involvement in evaluation of safety in Oral antineoplastic treatment: a failure mode and effects analysis in patients and health care professionals. Qual Manag Health Care. 2019;28(1): 33-8. https://doi.org/10.1097/QMH.0000000000000199.

69. McDermott AM, Kidd P, Gately M, et al. Restructuring of the diabetes day Centre: a pilot lean project in a tertiary referral Centre in the west of Ireland BMJ Qual Saf. 2013;22:681-8. https://doi.org/10.1136/bmjqs-2012-001676.

70. Brown L. Improving histopathology turnaround time: a process management approach. Curr Diagn Pathol. 2004;10:444-52. https://doi.org/1 0.1016/j.cdip.2004.07.008

71. Holleran L, Baker S, Cheng C, Wilson J, Mickelson R, Kazana I, MessingerRapport B, Shahin J, Cully J, Naik AD, Godwin KM. Using multisite process mapping to aid care improvement: an examination of inpatient suicidescreening procedures. J Healthc Qual. 2019;41(2):110-7. https://doi.org/10.1 097/JHQ.0000000000000182

72. Ogunwole SM, Phillips J, Gossett A, Downs JR. Putting veterans with heart failure FIRST improves follow-up and reduces readmissions. BMJ Open Qual. 2019;8(1):e000386. https://doi.org/10.1136/bmjoq-2018-000386.

73. Alexander L, Moore S, Salter N, et al. Lean management in a liaison psychiatry department: implementation, benefits and pitfalls. BJPsych Bulletin. 2020:44:18-25. https://doi.org/10.1192/bjb.2019.64.

74. Jester B, Schwerzmann J, Mustaquim D, Aden T, Brammer L, Humes R, Shult P, Shahangian S, Gubareva L, Xu X, Miller J. Mapping of the US domestic influenza virologic surveillance landscape. Emerg Infect Dis. 2018 Jul;24(7): 1300-6. https://doi.org/10.3201/eid2407.180028.

75. Alkandari M, Ryan K, Hollywood A. The experiences of people living with peripheral neuropathy in Kuwait-a process map of the patient journey. Pharmacy (Basel). 2019;7. https://doi.org/10.3390/pharmacy7030127. 
76. Keen A, Thoele K, Newhouse R. Variation in SBIRT delivery among acute care facilities. Nurs Outlook. 2020;68:162-8. https://doi.org/10.1016/j. outlook.2019.09.001.

77. Jallon R, Imbeau D, de Marcellis-Warin N. A process mapping model for calculating indirect costs of workplace accidents. J Saf Res. 2011;42(5):33344. https://doi.org/10.1016/j.jsr.2011.06.008

78. Bhavsar NA, Bloom K, Nicolla J, et al. Delivery of community-based palliative care: findings from a time and motion study. J Palliat Med. 2017;20:1120-6. https://doi.org/10.1089/jpm.2016.0433.

79. Forrester JA, Koritsanszky LA, Amenu D, et al. Developing Process Maps as a Tool for a Surgical Infection Prevention Quality Improvement Initiative in Resource-Constrained Settings. J Am Coll Surgeons. 2018;226:1103-16.e3. https://doi.org/10.1016/j.jamcollsurg.2018.03.020.

80. Vogelsmeier AA, Halbesleben JRB, Scott-Cawiezell JR. Technology implementation and workarounds in the nursing home. J Am Med Informatics Assoc. 2008;15:114-9. https://doi.org/10.1197/jamia.M2378.

81. Welch A. Process mapping occupational therapy activity within a medical admissions unit. Br J Occup Ther. 2002;65:158-64. https://doi.org/10.1177/03 0802260206500402.

82. Yazici C, Abdelmalak H, Gupta S, Shmagel A, Albaddawi E, Tsang V, Potts S, Arora VM. Sustainability and effectiveness of a quality improvement project to improve handoffs to night float residents in an internal medicine residency program. J Grad Med Educ. 2013;5(2):303-8. https://doi.org/10.43 00/JGME-D-12-00175.1.

83. Black M, Singh V, Belostotsky V, Roy M, Yamamura D, Gambarotto K, Lau K Kam AJ. Process mapping in a pediatric emergency department to minimize missed urinary tract infections. Int J Pediatr. 2016;2016:2625870-4. https://doi.org/10.1155/2016/2625870.

84. Hutchison A-M, Laing $H$, Williams $P$, Bodger $O$, Topliss $C$. The effects of a new Tendo-Achilles pathway (TAP) on an orthopaedic department- a quality improvement study. Musculoskelet Sci Pract. 2019;39:67-72. https:// doi.org/10.1016/j.msksp.2018.11.002.

85. Steckowych K, Smith M. Primary care workflow process mapping of medication-related activities performed by non-provider staff: a pilot project's approach. Res Soc Adm Pharm. 2019;15(9):1107-17. https://doi. org/10.1016/j.sapharm.2018.09.014.

86. Simkiss DE. Integrated care pathway to promote the health of looked after children. J Integr Care Pathways. 2005;9(3):123-8. https://doi.org/10.1177/14 7322970500900307.

87. Aung S. A bronchiolitis integrated care pathway for children. International Journal of Care Pathways. 2013;16(1):3-8. https://doi.org/10.1258/jicp.2012. 011023.

88. Ashley L. Integrating cancer survivors' experiences into UK cancer registries: design and development of the ePOCS system (electronic patient-reported outcomes from Cancer survivors). Br J Cancer. 2011;105. https://doi.org/10.1 038/bjc.2011.424.

89. Oetgen ME, Martin BD, Gordish-Dressman H, et al. Effectiveness and sustainability of a standardized care pathway developed with use of lean process mapping for the treatment of patients undergoing posterior spinal fusion for adolescent idiopathic scoliosis. J Bone Joint Surg Am. 2018;100: 1864-70. https://doi.org/10.2106/JBJS.18.00079.

90. Tseng P, Kaplan RS, Richman BD, et al. Administrative costs associated with physician billing and insurance-related activities at an academic health care system. JAMA. 2018;319:691-7. https://doi.org/10.1001/jama.2017.19148.

91. Laviana AA, Ilg AM, Veruttipong $D$, et al. Utilizing time-driven activity-based costing to understand the short- and long-term costs of treating localized, low-risk prostate cancer. Cancer. 2016;122:447-55. https://doi.org/10.1002/ cncr.29743.

92. McLaughlin N, Burke MA, Setlur NP, Niedzwiecki DR, Kaplan AL, Saigal C, Mahajan A, Martin NA, Kaplan RS. Time-driven activity-based costing: a driver for provider engagement in costing activities and redesign initiatives. Neurosurg Focus. 2014;37(5):E3. https://doi.org/10.3171/2014.8.FOCUS14381.

93. Akhavan S, Ward L, Bozic K, et al. Time-driven Activity-based Costing More Accurately Reflects Costs in Arthroplasty Surgery. Clinical Orthopaedics \& Related Res. 2016;474:8-15 8p. https://doi.org/10.1007/s11999-015-4214-0.

94. Erhun F, Mistry B, Platchek T, et al. Time-driven activity-based costing of multivessel coronary artery bypass grafting across national boundaries to identify improvement opportunities: study protocol. BMJ Open. 2015;5: e008765. https://doi.org/10.1136/bmjopen-2015-008765.

95. Inverso G, Lappi MD, Flath-Sporn SJ, Heald R, Kim DC, Meara JG. Increasing value in plagiocephaly care: a time-driven activity-based costing pilot study.
Ann Plast Surg. 2015;74(6):672-6. https://doi.org/10.1097/SAP 0000000000000002 .

96. Johnson JK, Farnan JM, Barach P, Hesselink G, Wollersheim H, Pijnenborg L, Kalkman C, Arora VM, on behalf of the HANDOVER Research Collaborative. Searching for the missing pieces between the hospital and primary care: mapping the patient process during care transitions. BMJ Qual Saf. 2012; 21(Suppl 1):i97-105. https://doi.org/10.1136/bmjqs-2012-001215.

97. Vandborg MP, Edwards K, Kragstrup J, Vedsted P, Hansen DG, Mogensen O. A new method for analyzing diagnostic delay in gynecological cancer. Int J Gynecol Cancer. 2012;22(5):712-7. https://doi.org/10.1097/IGC.0b013e31824 c6d0e.

98. O'Mara MS, Ramaniuk A, Graymire V, Rozzell M, Martin S. Lean methodology for performance improvement in the trauma discharge process. J Trauma Acute Care Surg. 2014;77(1):137-42. https://doi.org/10.1097/TA. 0000000000000261.

99. Oliver S, Bosworth A. Exploring the healthcare journey of patients with rheumatoid arthritis: a mapping project - implications for practice. Musculoskeletal Care. 2008;6(4):247-66. https://doi.org/10.1002/msc.139.

100. Kricke GS, Carson MB, Lee YJ, et al. Leveraging electronic health record documentation for Failure Mode and Effects Analysis team identification. J Am Med Informatics Assoc. 2016;23:N.PAG. https://doi.org/10.1093/jamia/ ocw083.

101. Jones DEJ, Sutcliffe K, Pairman J, Wilton K, Newton JL. An integrated care pathway improves quality of life in primary biliary cirrhosis. QJM. 2008 101(7):535-43. https://doi.org/10.1093/qjmed/hcn043.

102. Teixeira FC, de Almeida CE, Saiful HM. Failure mode and effects analysis based risk profile assessment for stereotactic radiosurgery programs at three cancer centers in Brazil. Med Phys. 2016;43(1):171-8. https://doi.org/10.111 8/1.4938065.

103. Sorrentino P. Use of failure mode and effects analysis to improve emergency department handoff processes. Clin Nurse Spec. 2016;30(1):2837. https://doi.org/10.1097/NUR.0000000000000169.

104. Ibanez-Rosello B, Bautista JA, Bonaque J, et al. Failure modes and effects analysis of total skin electron irradiation technique. Clin Transl Oncol. 2018; 20:330-65. https://doi.org/10.1007/s12094-017-1721-3.

105. Manger RP, Paxton AB, Pawlicki T, et al. Failure mode and effects analysis and fault tree analysis of surface image guided cranial radiosurgery. Med Phys. 2015;42:2449-61. https://doi.org/10.1118/1.4918319.

106. Howard I, Castle N, Al Shaikh LA. Application of a healthcare failure modes and effects analysis to identify and mitigate potential risks in the implementation of a National Prehospital Pediatric Rapid Sequence Intubation Program. J Patient Saf Published Online First. 2017. https://doi. org/10.1097/PTS.0000000000000454.

107. Howard I, Castle N, Al Shaikh L, et al. Understanding system-focused barriers to the identification and reporting of medication errors and adverse drug events in emergency medical services. Drugs Ther Perspect. 2019;35(6):28595. https://doi.org/10.1007/s40267-019-00628-6.

108. Egan S, Murphy PG, Fennell JP, et al. Using Six Sigma to improve once daily gentamicin dosing and therapeutic drug monitoring performance. BMJ Quality \& Safety. 2012;21:1042-51 10p. https://doi.org/10.1136/bmjqs-2012-000824.

109. Sujan M, Chessum P, Rudd M. Managing competing organizational priorities in clinical handover across organizational boundaries. J Health Services Rese Policy. 2015;20:17-25.

110. Arafeh M, Barghash MA, Haddad N, Musharbash N, Nashawati D, alBashir A, Assaf F. Using six sigma DMAIC methodology and discrete event simulation to reduce patient discharge time in King Hussein Cancer center. J Healthcare Engineering. 2018;2018:e3832151. https:// doi.org/10.1155/2018/3832151 1, 18

111. Patterson ES, Lowry SZ, Ramaiah M, et al. Improving Clinical Workflow in Ambulatory Care: Implemented Recommendations in an Innovation Prototype for the Veteran's Health Administration. EGEMS (Wash DC). 2015; 3:1149. https://doi.org/10.13063/2327-9214.1149.

112. Tyler A, Boyer A, Martin S, Neiman J, Bakel LA, Brittan M. Development of a discharge readiness report within the electronic health record-a discharge planning tool. J Hosp Med. 2014;9(8):533-9. https://doi.org/10.1002/ jhm.2212.

113. Jenkings KN. Implementation, change management and benefit realization: investigating the utility of ethnographically enriched process maps. Health Inform J. 2007;13:57-69. https://doi.org/10.1177/1460458207073646.

114. Staccini $P$, Joubert M, Quaranta J-F, et al. Mapping care processes within a hospital: from theory to a web-based proposal merging enterprise 
modelling and ISO normative principles. Int J Med Inform. 2005;74:335-44. https://doi.org/10.1016/j.ijmedinf.2004.07.003.

115. McDonald SA, Velasco E, llasi NT. Business process flow diagrams in tissue bank informatics system design, and identification and communication of best practices: the pharmaceutical industry experience. Biopreservation and Biobanking. 2010;8(4):203-9. https://doi.org/10.1089/bio.2010.0020.

116. Aaronson E, Mort E, Soghoian S. Mapping the process of emergency care at a teaching hospital in Ghana. Healthcare. 2017;5:214-20. https://doi.org/10.1 016/j.hjdsi.2016.12.001.

117. McCreight MS, Gilmartin HM, Leonard CA, et al. Practical use of process mapping to guide implementation of a care coordination program for rural veterans. J Gen Intern Med. 2019;34:67-74. https://doi.org/10.1007/s11606019-04968-x

118. Shayesteh SG, Kliewer G, Morrin L. The integration of quality management into chronic disease health services. Qual Manag Health Care. 2010;19(2): 156-63. https://doi.org/10.1097/QMH.0b013e3181dafde7.

119. Stans SE, Stevens JA, Beurskens AJ. Interprofessional practice in primary care: development of a tailored process model. J Multidiscip Healthc. 2013;6:13947. https://doi.org/10.2147/JMDH.S42594.

120. Manchaiah VKC, Stephens D, Lunner T. Communication partners' journey through their Partner's hearing impairment. Int J Otolaryngol. 2013;2013: 707910-1. https://doi.org/10.1155/2013/707910.

121. Manchaiah VKC, Stephens D, Meredith R. The patient journey of adults with hearing impairment: the patients' views. Clin Otolaryngol. 2011;36(3):227-34. https://doi.org/10.1111/j.1749-4486.2011.02320.x.

122. Manchaiah VKC, Stephens D. The "patient journey" of adults with suddenonset acquired hearing impairment: a pilot study. J Laryngol Otol. 2012;126: 475-81. https://doi.org/10.1017/S0022215111003197.

123. Aguilar-Savén RS. Business process modelling: review and framework. Int J Prod Econ. 2004;90(2):129-49. https://doi.org/10.1016/50925-5273 (03)00102-6.

124. Biazzo S. Process mapping techniques and organisational analysis: lessons from sociotechnical system theory. Bus Process Manag J. 2002;8(1):42-52. https://doi.org/10.1108/14637150210418629.

125. Dean JE. Using a multi-method, user centred, prospective hazard analysis to assess care quality and patient safety in a care pathway. BMC Health Serv Res. 2007;7(1). https://doi.org/10.1186/1472-6963-7-89.

126. Holmes B, Best A, Davies $\mathrm{H}$, et al. Mobilising knowledge in complex health systems : a call to action. Evidence and policy. 2016;13(3):539-60. https:// doi.org/10.1332/174426416X14712553750311.

127. Batalden P. Getting more health from healthcare: quality improvement must acknowledge patient coproduction —an essay by Paul Batalden. BMJ. 2018;362:k3617. https://doi.org/10.1136/bmj.k3617.

128. Chandra C, He J, Liu Z, Ruohonen T. Some promising areas for IS research in the hospital industry: implications from a case study of operating room scheduling. Health Technol. 2013;3(1):65-72. https://doi.org/10.1007/s12553013-0042-y

129. Persoon TJ, Zaleski MS, Cohen MB. Improving pap test turnaround time using external benchmark data and engineering process improvement tools. Am J Clin Pathol. 2002;1 18(4):527-33. https://doi.org/10.1309/20NXVJUK-VADH-51T8.

130. Simon RW, Canacari EG. A practical guide to applying lean tools and management principles to health care improvement projects. AORN J. 2012; 95(1):85-3. https://doi.org/10.1016/j.aorn.2011.05.021.

131. Walshe K. Understanding what works - and why -in quality improvement: the need for theory-driven evaluation. Int J Qual Health Care. 2007;19:57-9. https://doi.org/10.1093/intqhc/mzm004.

132. Calder LA, Forster AJ, Stiell IG, et al. Mapping out the emergency department disposition decision for high-acuity patients. Ann Emerg Med. 2012;60:567-576.e4. https://doi.org/10.1016/j.annemergmed.2012.04.013.

133. Dilts DM, Sandler AB, Baker M, Cheng SK, George SL, Karas KS, McGuire S, Menon GS, Reusch J, Sawyer D, Scoggins M, Wu A, Zhou K, Schilsky RL, Case of Cancer and Leukemia Group B. Processes to activate phase III clinical trials in a cooperative oncology group: the case of cancer and leukemia group B. J Clin Oncol. 2006;24(28):4553-7. https://doi. org/10.1200/JCO.2006.06.7819.

134. Goodwin-Wilson C, Watkins M, Gardner-Elahi C. Developing evidence-based process maps for spinal cord injury rehabilitation. Spinal Cord. 2010;48(2): 122-7. https://doi.org/10.1038/sc.2009.94.

135. Lyhne S, Georgiou A, Marks A, et al. Towards an understanding of the information dynamics of the handover process in aged care settings-a prerequisite for the safe and effective use of ICT. Int J Med Inf. 2012;81:45260. https://doi.org/10.1016/j.jimedinf.2012.01.013.

136. Lin SY, Gavney D, Ishman SL, Cady-Reh J. Use of lean sigma principles in a tertiary care otolaryngology clinic to improve efficiency. Laryngoscope. 2013;123(11):2643-8. https://doi.org/10.1002/lary.24110.

137. Croskerry P. Context is everything or how could I have been that stupid? Healthc Q. 2009;12 Spec No Patient:e171-6. https://doi.org/10.12927/hcq.2 009.20945.

138. Øvretveit J. Understanding the conditions for improvement: research to discover which context influences affect improvement success. BMJ Qual Saf. 2011;20(Suppl 1):i18-23. https://doi.org/10.1136/bmjqs.2010.045955.

139. Dy SM, Taylor SL, Carr LH, et al. A framework for classifying patient safety practices: results from an expert consensus process. BMJ Qual Saf. 2011;20: 618-24. https://doi.org/10.1136/bmjqs.2010.049296.

140. Almassi N, Glass KE, Lonzer JL, Urbanek DS, Grivas P, Rini B, Garcia J, Stephenson AJ, Klein EA, Krishnamurthi V. Identifying institutional causes of delay to radical cystectomy among patients with high risk bladder cancer treated at a tertiary referral center using process map analysis. Urol Pract. 2018 Sep;5(5):383-90. https://doi.org/10.1016/j.urpr.2017.08.003.

141. Bibi Y, Cohen AD, Goldfarb D, Rubinshtein E, Vardy DA. Intervention program to reduce waiting time of a dermatological visit: managed overbooking and service centralization as effective management tools. Int J Dermatol. 2007;46(8):830-4. https://doi.org/10.1111/j.1365-4632.2007.03078.x

142. Britton MC, Petersen-Pickett J, Hodshon B, et al. Mapping the care transition from hospital to skilled nursing facility. J Eval Clin Pract. 2019;26(3):786-90. https://doi.org/10.1111/jep.13238.

143. Cadwell K, Brimdyr K, Phillips R. Mapping, measuring, and analyzing the process of skin-to-skin contact and early breastfeeding in the first hour after birth. Breastfeed Med. 2018;13:485-92. https://doi.org/10.1089/ bfm.2018.0048.

144. Campling N, Cummings A, Myall M, Lund S, May CR, Pearce NW, Richardson A. Escalation-related decision making in acute deterioration: a retrospective case note review. BMJ Open. 2018;8(8):e022021. https://doi.org/10.1136/ bmjopen-2018-022021.

145. Chand S. Improving patient flow at an outpatient clinic : study of sources of variability and improvement factors. Health Care Management Science. 2009;12:325-40. https://doi.org/10.1007/s10729-008-9094-3.

146. DeGirolamo K, D'souza K, Hall W, Joos E, Garraway N, Sing CK, McLaughlin P, Hameed M. Process mapping as a framework for performance improvement in emergency general surgery. Can J Surg. 2018 Feb;61(1):138. https://doi.org/10.1503/cjs.004417.

147. Drew B, Angeli F, Dave K, et al. Impact of patients' healthcare payment methods on hospital discharge process: evidence from India. Int J Health Plann Manag. 2016;31:e158-74. https://doi.org/10.1002/hpm.2310.

148. Halbesleben JR, Savage GT, Wakefield DS, Wakefield BJ. Rework and workarounds in nurse medication administration process: implications for work processes and patient safety. Health Care Manag Rev. 2010;35(2):12433. https://doi.org/10.1097/HMR.0b013e3181d116c2.

149. Halvorson S, Wheeler B, Willis M, et al. A multidisciplinary initiative to standardize intensive care to acute care transitions. Int J Qual Health Care. 2016;28:615-25. https://doi.org/10.1093/intghc/mzw076.

150. Holbrook A, Bowen JM, Patel $H$, et al. Process mapping evaluation of medication reconciliation in academic teaching hospitals: a critical step in quality improvement. BMJ Open. 2016;6:e013663. https://doi.org/10.1136/ bmjopen-2016-013663.

151. Hummel J, Evans PC, Lee H. Medication reconciliation in the emergency department: opportunities for workflow redesign. BMJ Qual Saf. 2010;19(6): 531-5. https://doi.org/10.1136/qshc.2009.035121.

152. Jensen JL, Croskerry P, Travers AH. Consensus on paramedic clinical decisions during high-acuity emergency calls: results of a Canadian Delphi study. CJEM, Can j emerg med care. 2011;13:310-8. https://doi.org/10.2310/ 8000.2011.110405.

153. Juanola Roura X, Collantes Estevez E, Leon Vazquez F, et al. Reccomendations for the detection, study and referral of inflammatory lowback pain in primary care. Reumatol clin. 2015;11(2):90-8. https://doi.org/1 0.1016/j.reumae.2014.04.006

154. Kim B, McCullough MB, Simmons MM, Bolton RE, Hyde J, Drainoni ML, Fincke BG, Mclnnes DK. A novel application of process mapping in a criminal justice setting to examine implementation of peer support for veterans leaving incarceration. Health justice. 2019;7(1):1-1. https://doi.org/1 0.1186/s40352-019-0085-x. 
155. Klaiman T, O'Connell K, Stoto MA. Learning from successful school-based vaccination clinics during 2009 pH1N1. J Sch Health. 2014;84:63-9. https:/ doi.org/10.1111/josh.12119.

156. Lima Guimarães MF, Ramos Freire EM, Martins da Silva D, et al. PROCESS MAPPING: VIDEO-ASSISTED SURGERY INSTRUMENT FLOW. J NurS UFPE / Revista de Enfermagem UFPE. 2016;10:1162-9.

157. Lubliner M, Cole-Sinclair M, Kenneally A, Street A, van de Vreede M, Walsh MK. Minimising medication mishap: introducing a warfarin safety strategy. J Pharm Res. 2005;35(4):266-70. https://doi.org/10.1002/j.2055-2335.2005. tb00360.x.

158. Ngwenya N, Ambler J, Archary M. Qualitative situational analysis of palliative care for adolescents with cancer and HIV in South Africa: healthcare worker perceptions. BMJ Open. 2019;9:e023225. https://doi.org/10.1136/bmjopen-2 018-023225.

159. Peebles E, Subbe CP, Hughes P, Gemmell L. Timing and teamwork-an observational pilot study of patients referred to a rapid response team with the aim of identifying factors amenable to re-design of a rapid response system. Resuscitation. 2012;83(6):782-7. https://doi.org/10.1016/j.resuscita tion.2011.12.019.

160. Robertson SK, Manson K, Fioratou E. IMCI and ETAT integration at a primary healthcare facility in Malawi: a human factors approach. BMC Health Serv Res. 2018:18:1014. https://doi.org/10.1186/s12913-018-3803-5.

161. Schubert L, Liu A, Gan G, Amini A, Hutchison R, Ernest J, Thornton D, Stoehr S, Hinman B, Stuhr K, Westerly D, Schefter T, Fisher C. Practical implementation of quality improvement for high-dose-rate brachytherapy. Pract Radiation Oncol. 2016:6(1):34-43. https://doi.org/10.1016/jprro.2015.09.003.

162. Shahan C, DeJesus C, McCall M, Hampton F, Herring T, Davis J, Patel A, Gomillion S, Maltby B. Reduction of Failed Whole Blood Donor Testing Runs on the Roche Cobas s 201 System. In2017 AABB Annual Meeting 2017. AABB.

163. Sharma HR, Rozen WM, Mathur B, Ramakrishnan V. 100 steps of a DIEP flap-a prospective comparative cohort series demonstrating the successful implementation of process mapping in microsurgery. Plast Reconstr Surg Glob Open. 2019;7(1):e2016. https://doi.org/10.1097/GOX.0000000000002016.

164. Shelton SR, Nelson CD, McLees AW, et al. Building performance-based accountability with limited empirical evidence: performance measurement for public health preparedness. Disaster med public health prep. 2013;7(4): 373-9. https://doi.org/10.1017/dmp.2013.20.

165. Smiley K, Ofori L, Spangler C, Acquaah-Arhin R, Deh D, Enos J, Manortey S, Baiden F, Finlayson S, Price R, McCrum M. Safety culture and perioperative quality at the Volta River Authority Hospital in Akosombo, Ghana. World J Surg. 2019;43(1):16-23. https://doi.org/10.1007/s00268-018-4763-y.

166. Tariq A, Georgiou A, Raban M, Baysari MT, Westbrook J. Underlying risk factors for prescribing errors in long-term aged care: a qualitative study. BMJ Qual Saf. 2016;25(9):704-15. https://doi.org/10.1136/bmjas-2015-004589.

167. Toouli G, Georgiou A, Westbrook J. Changes, disruption and innovation: an investigation of the introduction of new health information technology in a microbiology laboratory. J Pathol Inform. 2012;3:16. https://doi.org/10.41 03/2153-3539.95128.

168. Turner S, Vasilakis C, Utley M, Foster P, Kotecha A, Fulop NJ. Analysing barriers to service improvement using a multi-level theory of innovation: the case of glaucoma outpatient clinics. Sociol Health IIness. 2018;40(4): 654-69. https://doi.org/10.1111/1467-9566.12670.

169. Tyson SF, Woodward-Nutt K, Plant S. How are balance and mobility problems after stroke treated in England? An observational study of the content, dose and context of physiotherapy. Clin Rehabil. 2018;32(8):114552. https://doi.org/10.1177/0269215518777789

170. Weir NM, Newham R, Corcoran ED, Al-Gethami AA, Abd Alridha AM, Bowie P, Watson A, Bennie M. Application of process mapping to understand integration of high risk medicine care bundles within community pharmacy practice. Res Soc Adm Pharm. 2018;14(10):944-50. https://doi.org/10.1016/j. sapharm.2017.11.009.

\section{Publisher's Note}

Springer Nature remains neutral with regard to jurisdictional claims in published maps and institutional affiliations.

Ready to submit your research? Choose BMC and benefit from:

- fast, convenient online submission

- thorough peer review by experienced researchers in your field

- rapid publication on acceptance

- support for research data, including large and complex data types

- gold Open Access which fosters wider collaboration and increased citations

- maximum visibility for your research: over $100 \mathrm{M}$ website views per year

At BMC, research is always in progress.

Learn more biomedcentral.com/submissions 